\title{
APPLICATION OF HALLOYSITE GEOPOLYMERS TO REMOVAL OF METHYL BLUE FROM AQUEOUS SOLUTION
}

\author{
*Elżbieta Sitarz-Palczak ${ }^{1}$ and Jan Kalembkiewicz ${ }^{1}$ \\ ${ }^{1}$ Faculty of Chemistry, Rzeszow University of Technology, Poland \\ *Corresponding Author, Received: 15 Sept. 2021, Revised: 29 Oct. 2021, Accepted: 21 Nov. 2021
}

\begin{abstract}
Disposal of industrial wastewater from the dyeing industry is an important issue due to the negative impact of wastewater from the dyeing industry on the environment, as well as the lack of universal methods of disposal of this type of wastewater. The paper defines the ability to use geopolymers obtained from halloysite as an adsorbent for the removal of the methyl blue (MB) from an aqueous solution. The influence of initial MB concentration, contact time, and $\mathrm{pH}$ on the efficiency of methyl blue removal from aqueous solutions was assessed experimentally. The balance and kinetics of MB sorption on geopolymers obtained from halloysite were described. The Fourier Transform Infrared Spectroscopy technique was used to determine the mechanism of photocatalytic degradation of MB. The applied geopolymers show high MB removal efficiency at the level of about $90 \%$, which increases with the increase of its concentration and the time of the sorption experiment. The results indicated that the highest efficiency of dye removal was found at $\mathrm{pH} \geq 9$. The sorption process occurs according to the Langmuir model, according to the kinetic equation of the pseudo-final order. The photocatalytic MB degradation process can be classified as Advanced Oxidation Processes (AOPs). The process proposed in the paper is simple and economical and the results can be used to remediate industrial wastewater from the dye industry contaminated with MB.
\end{abstract}

Keywords: Geopolymer, Adsorption, Methyl Blue, AOPs

\section{INTRODUCTION}

One of the most serious sources of pollution and contamination of the aquatic environment is industrial wastewater containing dyes in its composition [1]. Coloring agents are organic and organometallic molecules which, depending on their nature, may exhibit toxic or carcinogenic properties. The presence of coloring compounds has a negative impact on the environment. Even a small number of dyes may cause coloring of large volumes of water solutions and disrupt life processes in water, i. e. inhibition of photosynthesis and an increase in chemical and biological oxygen demand. In addition, some dyes are extremely harmful to organisms living in water due to the presence of metal ions as well as chloride ions in their structure [2]. The compounds giving the highest toxicity indices are basic dyes and diazo direct dyes. In addition, azo dyes in particular exhibit carcinogenic and mutagenic effects by breaking down the azo bond to form carcinogenic aromatic amines. Many coloring substances can be seen in aqueous solution sat concentrations as low as $1 \mathrm{mg} / \mathrm{dm}^{3}$ [3]. Such dyes include methyl blue used mainly in the textile industry (trade name - aniline blue) and for staining medical preparations to show the presence of Candida [4].

The treatment of industrial wastewater containing coloring compounds is a complex topic under investigation. The problem is the continuous change in the technology of production of dyes, as well as their use in the technological process. Due to the differences in the materials used and the industrial method itself, it is not possible to unambiguously determine the universal qualitative and quantitative composition of industrial wastewater, and therefore it is not possible to effectively cleanse it of undesirable substances using a single method. Therefore, it is necessary in many cases to use combined techniques.

There are a number of wastewater treatment processes ranging from biological methods using activated sludge to mechanical and chemical methods. They differ from each other in the way they affect pollution and the substances used, as well as the conditions. They show varying degrees of effectiveness in removing wastewater from the dye industry. Mechanical wastewater treatment includes methods that occur in every wastewater treatment plant and are applied to any type of pollutant, regardless of its qualitative and quantitative composition. According to literature data, conducting a two-hour method of mechanical treatment of wastewater from the dye industry by sedimentation leads to a $40-50 \%$ reduction in suspended solids, a $15-20 \%$ reduction in the color of the wastewater, and a reduction in the value of biological oxygen demand by about 8-40\% [5]. Removal of wastewater from the dye industry using the activated sludge method is one of the most economical methods, however, it does not result in 
high color reduction. Among the chemical methods, precipitation with e.g., lime and adsorption with e.g., activated carbon are considered as one of the most effective methods [6]. Currently there is a lot of research on replacing activated carbon, which has the disadvantage of high price, with waste sorbents, which have low processing costs and wide availability. Removal of dye substances from water is also possible through Advanced Oxidation Processes (AOPs). A typical example of an oxidant used in this technology is ozone [7]. Ozonation can proceed as molecular ozone reactions or through oxidation processes realized by the generation of free radicals, in particular hydroxyl radicals [8]. The application of this type of oxidizing agent to wastewater from the textile industry leads to an $80 \%$ reduction in chemical oxygen demand [9].

\section{RESEARCH SIGNIFICANCE}

In this study, the feasibility of using geopolymers derived from halloysite as adsorbents for the removal of methyl blue (MB) from aqueous solutions was determined. The influence of experimental parameters such as $\mathrm{MB}$ initial concentration, experimental time and $\mathrm{pH}$ on $\mathrm{MB}$ degradation process was determined. The equilibrium and kinetics of adsorption process were described and the mechanism of photocatalytic degradation of MB was determined. The process proposed in the paper is simple and economical. he results can be used to remediate industrial wastewater from the dye industry contaminated with MB.

\section{EXPERIMENTAL}

\subsection{Materials and Method}

Geopolymers obtained from natural halloysite without activation (H/GEO) and activated halloysite, i.e., subjected to microwave activation (HA/GEO), constituted the research material. They were obtained by geopolymerization reaction from natural or activated halloysite using a mixture of sodium silicate $\mathrm{SiO}_{2} / \mathrm{Na}_{2} \mathrm{O}$ with solid $\mathrm{NaOH}$ as an alkaline activator. The ratio of solid component weight $[\mathrm{g}]$ to alkaline activator volume $\left[\mathrm{cm}^{3}\right]$ was 50:50. The exact synthesis process and geopolymerization conditions were described in detail in [10] and were the same as for geopolymers obtained from coal and biomass combustion ash. H/GEO and HA/GEO geopolymers were used in crushed form after being ground in a porcelain and agate mortar. The grain size of the geopolymers used was $100 \mu \mathrm{m}$. In addition, methyl blue (MB), a product commercially available under the name aniline blue, was used. It is a water-soluble dye from the acid group with the following summarized formula $\mathrm{C}_{32} \mathrm{H}_{25} \mathrm{~N}_{3} \mathrm{Na}_{2} \mathrm{O}_{9} \mathrm{~S}_{3}$. Its molar mass is $737.74 \mathrm{~g} / \mathrm{mol}$. It comes in the form of a dark blue powder [5].

\subsection{Research Metodology}

The study of photocatalytic degradation of MB by $\mathrm{H} / \mathrm{GEO}$ and HA/GEO included two steps sequentially; the first stage - the preparation of MB standard solutions and the preparation of the calibration curve constituting the relation $\mathrm{A}=$ $f\left(c_{M B}\right)$ and the second stage - studies on the influence of the initial concentration of $\mathrm{MB}$, experimental time and $\mathrm{pH}$ on the process of photocatalytic degradation of MB.

To determine the analytical wavelength, the spectrum of a MB solution at $650 \mathrm{~nm}$ was recorded using a UV-VIS spectrophotometer (model V-670, Jasco, Japan). From the analysis of the above spectrum (Fig. 1), it was found that the absorbance maximum occurs at a wavelength of $585 \mathrm{~nm}$. For the preparation of the standard curve, solutions of MB with the following initial concentrations: 5,10 , $25,40,50 \mathrm{mg} / \mathrm{dm}^{3}$ were prepared and then the absorbance for these solutions was measured at analytical wave length $=585 \mathrm{~nm}$. Based on the results obtained, the calibration curve constituting the relation $\mathrm{A}=\mathrm{f}(\mathrm{cMB})$ was prepared.

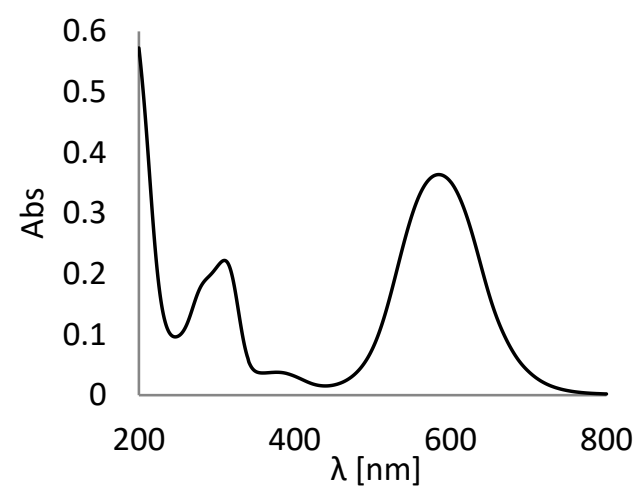

Fig.1 Absorption spectrum of $\mathrm{MB}$ solution at concentration of $10 \mathrm{mg} / \mathrm{dm}^{3}$ obtained at $\lambda=650 \mathrm{~nm}$, $\mathrm{l}=1$, reference - water

In the next stage of the study, the effects of initial MB concentration (in the range of $1-100$ $\mathrm{mg} / \mathrm{dm}^{3}$ ), experiment duration (in the range of 5 $1440 \mathrm{~min})$ and solution $\mathrm{pH}(1-10)$ on the efficiency of $\mathrm{MB}$ removal process were determined. $0.1 \mathrm{M}$ $\mathrm{NaOH}$ or $0.1 \mathrm{M} \mathrm{HCl}$ was used to adjust the $\mathrm{pH}$ value. Experiments were conducted in a single component closed system using a geopolymer sample mass of $1.00 \mathrm{~g}$ and a volume of MB solution of $100 \mathrm{~cm}^{3}$. The resulting suspension was shaken at $293( \pm 0.5 \mathrm{~K})$ for $30 \mathrm{~min}$ at a rate of $\mathrm{v}=500 \mathrm{rpm}$ on a Vibramax 100 laboratory shaker (Heidolph Instruments, Germany). Further, the filtrate was filtered and the concentration of methyl blue was determined in the 
obtained filtrate by UV-VIS spectrophotometric method. On the basis of the obtained values of $\mathrm{MB}$ concentrations in the obtained solutions, the values of sorption capacity q and absorption coefficient A, whose value represents the \% of $\mathrm{MB}$ removal, were calculated. The sorption capacity q was determined using relation (1):

$$
q=\frac{\left(c_{0}-c\right)}{m} \cdot V
$$

where: q - sorption capacity of geopolymer [mg/g], $c_{o}$ - initial concentration of MB in solution $\left[\mathrm{mg} / \mathrm{dm}^{3}\right]$, c - concentration of $\mathrm{MB}$ in solution $\left[\mathrm{mg} / \mathrm{dm}^{3}\right], \mathrm{m}$ - mass of geopolymer sample [g], V volume of MB solution [ $\left.\mathrm{dm}^{3}\right]$.

The adsorption coefficient A [\%] was calculated according to equation (2):

$$
A=\frac{c_{0}-c}{c_{0}} \cdot 100 \%
$$

A description of the symbols is given with equation (1).

\subsection{Mechanism of Photocatalytic Degradation of Methyl Blue}

In order to determine the mechanism of photocatalytic degradation of $\mathrm{MB}$, samples of geopolymers obtained from inactivated halloysite (H/GEO) or activated halloysite (HA/GEO) were dried to constant weight at room temperature after the sorption experiment. After being powdered and grated in porcelain and agate mortar, they were destined for Fourier Transform Infrared Spectroscopic (FTIR) studies. Samples for testing were prepared by mixing about $0.5 \mathrm{mg}$ of geopolymer with $200 \mathrm{mg}$ of spectrally pure $\mathrm{KBr}$. Then they were subjected to pressing under vacuum at a pressure of $20 \mathrm{MPa}$. Absorption spectra of geopolymers of halloysite without activation (H/GEO) or halloysite activated (HA/GEO) obtained before and after photocatalytic degradation of $\mathrm{MB}$ were recorded in the fundamental range $4000-400 \mathrm{~cm}^{-1}$ with a resolution of $2 \mathrm{~cm}^{-1}$ using an FTIR spectrophotometer, (Alpha model, Bruker, Germany).

\section{RESULTS AND DISCUSSION}

\subsection{Effect of Experimental Parameters on the Efficiency of MB Removal}

\subsubsection{Initial concentration of $M B$}

Figure 2 and Table 1 show the dependence of the sorption parameters on the initial concentration of MB. For the geopolymers used, the adsorption coefficient values are at a high level. For halloysitebased geopolymer without activation (H/GEO), these values are in the range of 84-94\%. The highest value was obtained for $\mathrm{MB}$ concentration of 50 $\mathrm{mg} / \mathrm{dm}^{3}$. For the activated halloysite based geopolymer (HA/GEO), the values range from 92$96 \%$ and the highest value was obtained for the lowest MB concentration used - $5 \mathrm{mg} / \mathrm{dm}^{3}$. Based on the presented results, both geopolymers can be considered as good adsorbents for the removal of methyl blue from aqueous solutions.

Table 1 Summary of the adsorption coefficients for the adsorption of $\mathrm{MB}$ on H/GEO and HA/GEO geopolymers depending on the initial $\mathrm{MB}$ concentration

\begin{tabular}{ccccc}
\hline Geopolymer & \multicolumn{2}{c}{$\mathrm{H} / \mathrm{GEO}$} & \multicolumn{2}{c}{$\mathrm{HA} / \mathrm{GEO}$} \\
\hline $\begin{array}{c}\mathrm{c}_{\mathrm{o}} \\
{\left[\mathrm{mg} / \mathrm{dm}^{3}\right]}\end{array}$ & $\begin{array}{c}\mathrm{c} \\
{\left[\mathrm{mg} / \mathrm{dm}^{3}\right]}\end{array}$ & $\begin{array}{c}\mathrm{A} \\
{[\%]}\end{array}$ & $\begin{array}{c}\mathrm{c} \\
{\left[\mathrm{mg} / \mathrm{dm}^{3}\right]}\end{array}$ & $\begin{array}{c}\mathrm{A} \\
{[\%]}\end{array}$ \\
5.0 & 0.8 & 84.4 & 0.2 & 96.5 \\
10.0 & 1.3 & 86.8 & 0.4 & 96.4 \\
25.0 & 1.8 & 92.8 & 1.6 & 93.8 \\
50.0 & 2.8 & 94.3 & 3.9 & 92.1 \\
100.0 & 9.3 & 90.7 & 8.1 & 91.9 \\
\hline
\end{tabular}

From the graphs presented on the Figure 2, it can be concluded that in both cases of the geopolymers used, the dye removal efficiency increases with increasing initial concentration. This is evidenced by the determined values of the sorption capacity, equal to about $9.00 \mathrm{mg} / \mathrm{g}$. The high degree of $\mathrm{MB}$ binding suggests a strong interaction between these molecules and the active centers on the H/GEO and HA/GEO surfaces. However, the efficiency of MB removal from solutions decreases with increasing concentration of the solution used during the experiment. This is due to the fact that at low concentrations, more active centers located on the surface of geopolymers are available where MB can be bound. This promotes increased dye interaction with the geopolymer. A higher initial concentration of $\mathrm{MB}$ in solution, on the other hand, reduces the number of active sites with which interaction can occur because some of them are already occupied. This is associated with a decrease in MB removal efficiency.

The values of sorption capacity and adsorption coefficient are also affected by the porosity of geopolymers. The increasing number of pores increases the specific surface area of the solid and thus the number of active centers. On the basis of the results obtained, it can be concluded that HA/GEO geopolymer shows higher porosity and higher efficiency of MB removal from the solutions studied. Similar observations was reported for MB removal on mesoporous birnessite [11]. 


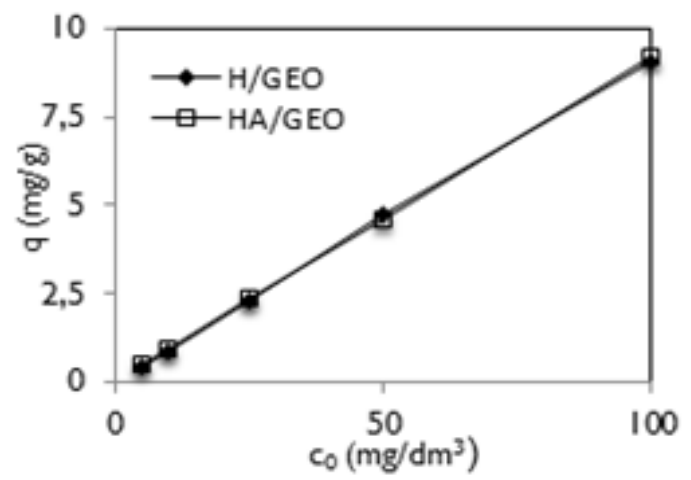

Fig.2 Dependence of the sorption capacity on the concentration of the initial MB solution for $\mathrm{H} / \mathrm{GEO}$, HA/GEO geopolymer

The values of sorption capacity and adsorption coefficient are also affected by the porosity of geopolymers. The increasing number of pores increases the specific surface area of the solid and thus the number of active centers. On the basis of the results obtained, it can be concluded that HA/GEO geopolymer shows higher porosity and higher efficiency of MB removal from the solutions studied. Similar observations was reported for MB removal on mesoporous birnessite [11].

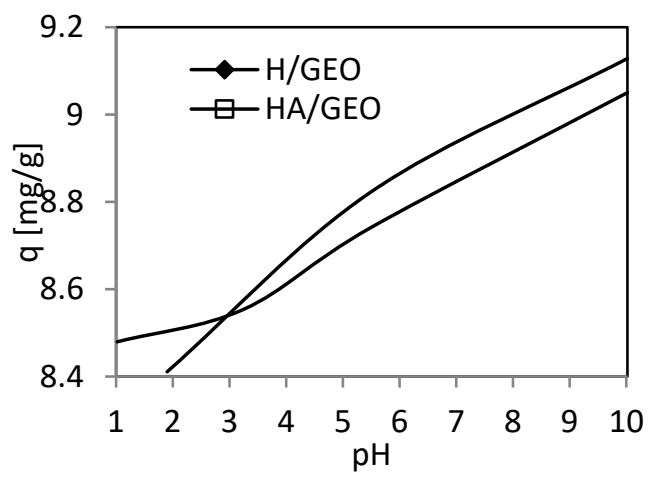

Fig.3 Dependence of sorption capacity on solution $\mathrm{pH}$ value for $\mathrm{H} / \mathrm{GEO}$ and $\mathrm{HA} / \mathrm{GEO}$ geopolymer

\subsection{2 $\mathrm{pH}$ of the solution}

The experiment was carried out using methyl blue solution with a concentration of $100 \mathrm{mg} / \mathrm{dm}^{3}$. The results obtained are shown in Fig. 3. By investigating the effect of $\mathrm{pH}$ on the efficiency of MB sorption process, it can be observed that the dye removal efficiency increased with increasing $\mathrm{pH}$ of the solution. This is evidenced by the determined sorption capacities and adsorption coefficients, which reached the highest values at $\mathrm{pH}$ equal to 10 . For the halloysite-based geopolymers tested, they are $9.13 \mathrm{mg} / \mathrm{g}$ and $91.3 \%$ for H/GEO and $9.05 \mathrm{mg} / \mathrm{g}$ and $90.5 \%$ for $\mathrm{HA} / \mathrm{GEO}$, respectively. Similar adsorption behaviors of $\mathrm{MB}$ were reported by several investigations [6]. This allows us to conclude that the optimal environment for the photocatalytic degradation of methyl blue is alkaline. This is associated with an increase in the concentration of hydroxyl ions, which are highly reactive free radicals.

\subsubsection{Contact time}

The effect of contact time on the removal of MB by the geopolymers is shown in Fig. 4 and Table 2 . On the basis of the tests performed, it can be concluded that at the initial stage of the process the absorption of the dye occurs very intensively and almost equally for both geopolymers. As the contact time increases, the sorption capacity values continue to increase and remain almost identical for both geopolymers - about $9.1 \mathrm{mg} / \mathrm{g}$. The rapid adsorption during the initial contact time is due to the presence of negatively charged active centers. As time passes, the number of available active centers on which a MB molecule can be bound decreases, resulting in a decrease in the efficiency of the dye removal process.

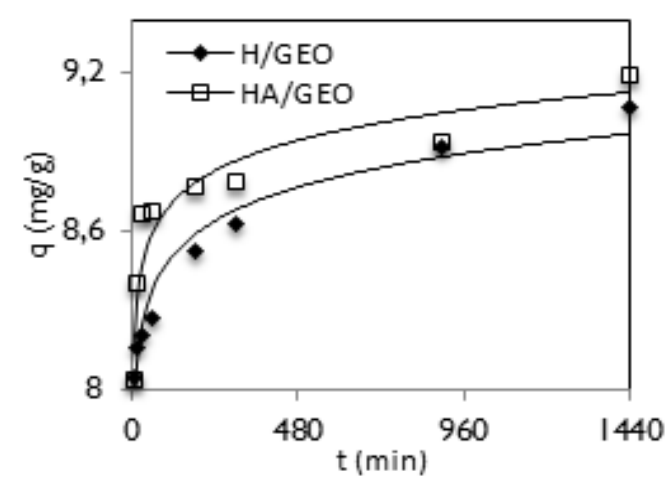

Fig.4 Dependence of sorption capacity on sorption time for MB solution with addition of geopolymer H/GEO and HA/GEO

Table 2 Comparison of adsorption coefficients values for $\mathrm{MB}$ adsorption process on $\mathrm{H} / \mathrm{GEO}$ and HA/GEO geopolymers depending on the contact time

\begin{tabular}{ccccc}
\hline Geopolymer & \multicolumn{2}{c}{ H/GEO } & \multicolumn{2}{c}{ HA/GEO } \\
\hline $\begin{array}{c}\mathrm{t} \\
{\left[\mathrm{min}^{3}\right]}\end{array}$ & $\begin{array}{c}\mathrm{c} \\
{\left[\mathrm{mg} / \mathrm{dm}^{3}\right]}\end{array}$ & $\begin{array}{c}\mathrm{A} \\
{[\%]}\end{array}$ & $\begin{array}{c}\mathrm{c} \\
{\left[\mathrm{mg} / \mathrm{dm}^{3}\right]}\end{array}$ & $\begin{array}{c}\mathrm{A} \\
{[\%]}\end{array}$ \\
5 & 19.5 & 80.5 & 19.6 & 80.4 \\
15 & 18.5 & 81.6 & 15.9 & 84.1 \\
30 & 17.9 & 82.1 & 13.3 & 86.7 \\
60 & 17.2 & 82.8 & 13.3 & 86.7 \\
180 & 14.7 & 85.3 & 12.2 & 87.8 \\
300 & 13.7 & 86.3 & 12.1 & 87.9 \\
900 & 11.6 & 89.3 & 11.4 & 89.4 \\
1440 & 9.3 & 90.7 & 8.1 & 91.9 \\
\hline
\end{tabular}


By comparing the two halloysite-based geopolymers, it can be concluded that the geopolymers used show a similar degree of $\mathrm{MB}$ removal from aqueous solutions. The adsorption process has an increasing character, which indicates that the equilibrium state has not been finally reached.

\subsection{Studies on Kinetics of MB Adsorption on Geopolymers}

In order to select the sorption isotherm equation best describing the adsorption of MB dye particles on H/GEO and HA/GEO, the experimental values were linearized. The following values of determined parameters were obtained: $\mathrm{c}_{\mathrm{e}}=13.8$ and $12.7 \mathrm{mg} / \mathrm{dm}^{3}$ for $\mathrm{H} / \mathrm{GEO}$ and $\mathrm{HA} / \mathrm{GEO}$, respectively; $t_{e}=265$ and $125 \mathrm{~min}$ for $\mathrm{H} / \mathrm{GEO}$ and $\mathrm{HA} / \mathrm{GEO}$, respectively; $\mathrm{q}_{\mathrm{e}}=8.62$ and $8.73 \mathrm{mg} / \mathrm{g}$ for H/GEO and HA/GEO, respectively. They are close to each other, suggesting that the physical modification of halloysite by sonification does not significantly affect the equilibrium of the $\mathrm{MB}$ adsorption process.

In order to determine the process kinetics, an attempt was made to fit the experimental data to commonly used kinetic equation models. Pseudofirst and pseudo-second order kinetic equations are usually used to describe the kinetics of dye sorption process on solids according to literature data $[15,16]$. On the basis of the performed calculations, kinetics on the H/GEO surface by the pseudoprimary equation is possible only for the first 180 min of the process, while for HA/GEO for $60 \mathrm{~min}$. Therefore, a pseudo-second order kinetic equation was used to describe the kinetics of MB adsorption on the surface of the studied geopolymers. Results of data matching obtained during the experiments to the pseudo-second order kinetic equation is shown in Fig. 5.

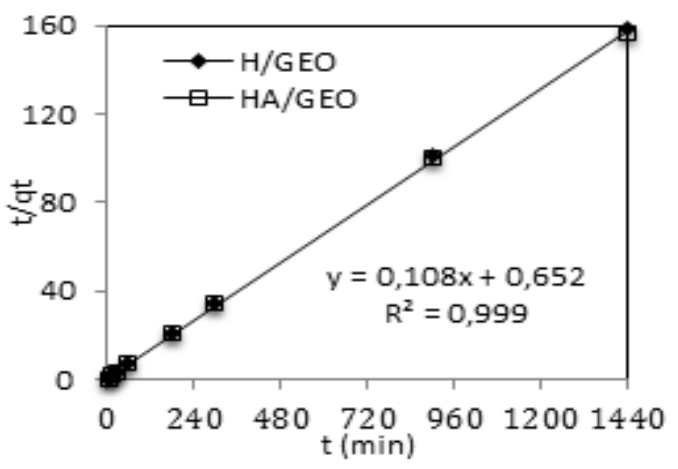

Fig.5 The relationship $\mathrm{t} / \mathrm{qt}=\mathrm{f}(\mathrm{t})$ describing the pseudo-second order kinetic equation for $\mathrm{MB}$ adsorption by H/GEO and HA/GEO geopolymer
The graphs produced indicate that the sorption mechanism of MB follows a pseudo-second order kinetic equation. This is evidenced by linear correlation coefficients $\mathrm{R}^{2}$ of 0.999 for both geopolymers. According to the theory of pseudosecond order kinetics, adsorption occurs by timedetermined surface diffusion [16].

In addition, Table 3 present a summary of the maximum adsorption capacity $\left(\mathrm{q}_{\max }\right)$ of the developed adsorbents for MB in aqueous solutions. A comparison with other reported adsorbents showed the $\mathrm{q}_{\max }$ value for the geopolymers used in this study is not very high and is a limitation of use of haloysite based geopolymers.

Table 3 Comparison of the obtained adsorption capacity with the developed adsorbents in literature

\begin{tabular}{ccc}
\hline Adsorbents & $\begin{array}{c}\mathrm{q}_{\max } \\
{[\mathrm{mg} / \mathrm{g}]}\end{array}$ & References \\
\hline $\begin{array}{c}\text { Coal fly ash based } \\
\text { geopolymer }\end{array}$ & 50.7 & {$[12]$} \\
$\begin{array}{c}\text { Biomass fly ash } \\
\text { geopolymer }\end{array}$ & 15.4 & {$[13]$} \\
$\begin{array}{c}\text { Phoshoric acid } \\
\text { base geopolymer } \\
\text { Haloysite based } \\
\text { geopolymer }\end{array}$ & 9.3 & {$[14]$} \\
\hline
\end{tabular}

An intermolecular diffusion model can also be used to determine the rate of the adsorption process. According to this model, the adsorption process is composed of the following steps: migration of the adsorbate to the sorbent surface; dye diffusion; intramolecular diffusion in the pores; adsorption on the sorbent surface.

The calculation results for the intermolecular diffusion model are substituted in Figure 6. For the halloysite-based geopolymer without activation (H/GEO), the value of the linear correlation coefficient is $\mathrm{R}^{2}=0.986$, indicating a high correlation of at values with $\mathrm{t}^{0.5}$ values. This suggests that intermolecular diffusion is the step that determines the rate of $\mathrm{MB}$ adsorption on this geopolymer in contrast to the HA/GEO geopolymer, for which the value of the linear correlation coefficient is at a low level $\left(\mathrm{R}^{2}=0.762\right)$. The kinetics of $\mathrm{MB}$ adsorption on the surface of a natural halloysite-based geopolymer (H/GEO) depends on intermolecular diffusion, which is the step that determines the rate of this process. The kinetics of $\mathrm{MB}$ adsorption on the surface of halloysite-activated geopolymer (HA/GEO) is controlled by liquid phase diffusion and intermolecular diffusion. 


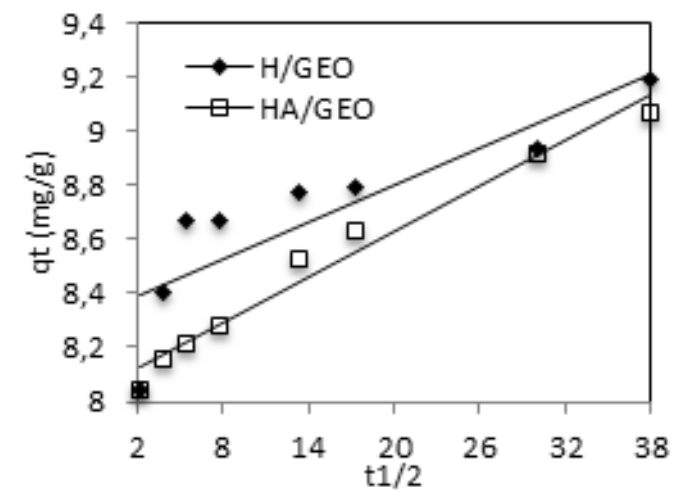

Fig.6 Intermolecular diffusion diagram for adsorption of $\mathrm{MB}$ by geopolymer $\mathrm{H} / \mathrm{GEO}$ and HA/GEO

\subsection{Equilibrium Studies of MB Adsorption on Geopolymers}

An important aspect is the description of the equilibrium occurring between the adsorbent and the adsorbate. Determination of adsorption isotherms allows to determine the relation between the amount of adsorbed substance and the solution concentration. In this way, much valuable information about the adsorption mechanism is obtained. Langmuir and Freundlich isotherm models are the most commonly used [13].

The relationship describing the Langmuir isotherm model is shown graphically in Figure 7.

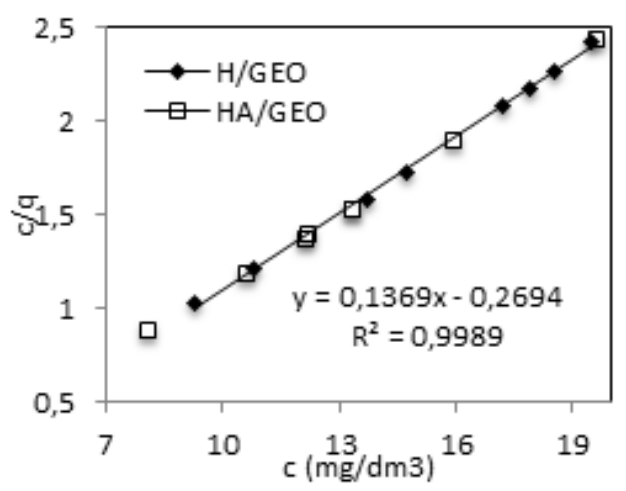

Fig.7 Langmuir isotherm for $\mathrm{MB}$ adsorption by geopolymer H/GEO and HA/GEO

From the obtained data, better Langmuir isotherm fit can be deduced for both raw (H/GEO) and activated (HA/GEO) halloysite-based geopolymer. This is evident from the value of the linear correlation coefficient. The $\mathrm{R}^{2}$ coefficient close to unity indicates the formation of monolayer on the adsorbent surface according to the assumptions of Langmuir isotherm.

There are active centers on the surface of the adsorbent that bind the methyl blue molecules. Only one molecule can be adsorbed on one active site and a decrease in the number of available sites causes a decrease in the efficiency of the dye removal process.

\subsection{Fourier Transform Infrared Spectroscopy Analysis}

In order to compare the changes occurring in the structure of geopolymers, Fourier Transform Infrared Spectroscopy spectra before and after the MB sorption process are presented in Fig. 8 and 9.

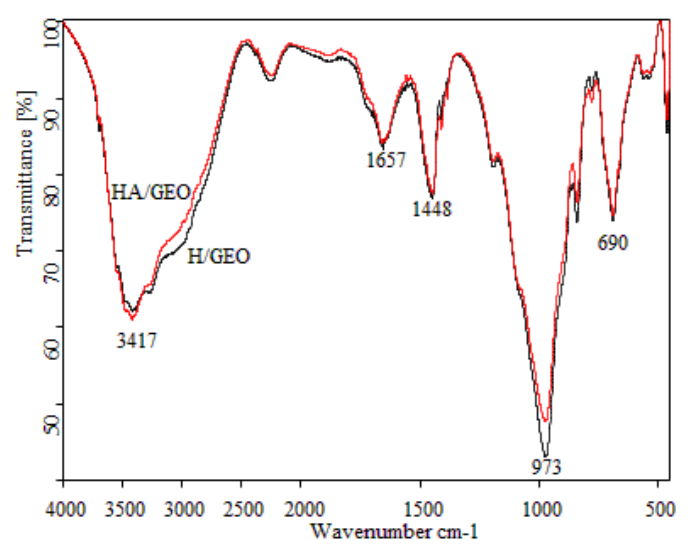

Fig.8 Summary of FTIR spectra for H/GEO and HA/GEO geopolymers before MB sorption

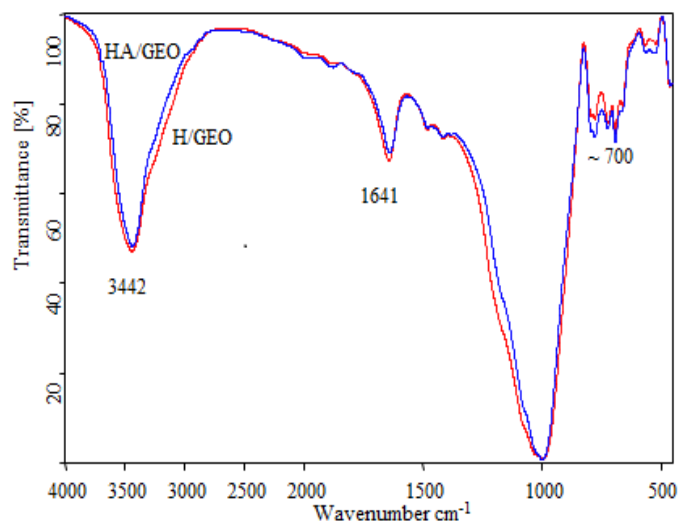

Fig.9 Summary of FTIR spectra for H/GEO and HA/GEO geopolymers after MB sorption

By analyzing the spectra of H/GEO and HA/GEO geopolymers, it can be seen that they are virtually identical. The band lying at $3416 \mathrm{~cm}^{-1}$, corresponding to the stretching vibrations of the hydroxyl group is slightly broadened, and also the signal at about $974 \mathrm{~cm}^{-1}$ originating from the asymmetric stretching vibrations of the outer $-\mathrm{OH}$ groups is slightly intensified. In both samples, the geopolymers are present in hydrated form, as evidenced by the intensity of the bands associated with the stretching vibrations of the hydroxyl groups at about $3445 \mathrm{~cm}^{-1}$. Significant differences are the band appearing at lower frequencies equal to $1641 \mathrm{~cm}^{-1}$ compared to the spectrum before sorption. This is a band characteristic for the stretching 
vibrations of $-\mathrm{C}=\mathrm{C}-$ and $-\mathrm{C}=\mathrm{N}$ - bonds, suggesting the presence of an aromatic ring coming from the MB dye molecule. A band decay was observed at $1448 \mathrm{~cm}^{-1}$ corresponding to the vibration of bridged bound water. Also, significant is the appearance of new bands in the $800-700 \mathrm{~cm}^{-1}$ range that originate from $-\mathrm{N}-\mathrm{H}$ - stretching vibrations. This indicates the presence of amino groups.

Table 4 gives a description of the bands appearing in the above spectra.

Table 4 Summary of the major bands on the FTIR spectra of halloysite-based geopolymers (H/GEO and HA/GEO

\begin{tabular}{ccc}
\hline & Assignment & References \\
\hline $3500-2900$ & Vibrations & {$[17]$} \\
& stretching & \\
& OH groups & \\
& Vibrations & {$[18]$} \\
& stretching & \\
& C=C and \\
& C=N bond \\
$1200-900$ & Asymmetric & {$[19]$} \\
& stretching \\
& (Si-O-Si and \\
& Al-O-Si) \\
& Asymmetric & \\
& stretching \\
& OH groups \\
\hline
\end{tabular}

Analysis of the Fourier Transform Infrared Spectroscopy spectra and determination of the changes in the position of individual bands showed that binding of the MB molecule occurs on the surface of both halloysite-based geopolymers.

\subsection{Mechanism of Photocatalytic Degradation of Methyl Blue}

The mechanism of dye binding by the sorbent depends on the chemical structure of the dye, the type and number of chromophore and auxochromic groups and their spatial configuration. Interactions of the type $\pi-\pi$ can occur between delocalized electrons of the aromatic rings of the dye. This type of interaction has been described in the paper [20]. This process belongs to the Advanced Oxidation Methods (AOPs). The mechanism of the process involves several steps. The first is the electrolytic dissociation of the dye in aqueous solution. The obtained cations are used to compensate the negative charge of geopolymer chains, which include $\left[\mathrm{SiO}_{4}{ }^{4-}\right]$ and $\left[\mathrm{AlO}_{4}{ }^{-}\right]$anions. Geopolymers are materials that have active centers on their surface that can form carbocations. The active centers on the surface of amorphous aluminosilicates, which are geopolymers, differ in structure, hence the reaction mechanism of the photocatalic degradation of methyl blue can be described in many ways [21-23], one of which is proposed in this work

In the structure of halloysite based geopolymers, apart from oxygen, silicon and aluminum content, metal oxides $\mathrm{Fe}_{2} \mathrm{O}_{3}$ and $\mathrm{TiO}_{2}$ are distinguished. They are a source of electrons whose emission takes place under the influence of UV radiation. The combination of the emitted electrons with water molecules results in the formation of hydroxyl radicals. The degradation of $\mathrm{MB}$ adsorbed on the geopolymer surface occurs by oxidation with hydroxyl radicals formed. The process follows the mechanism shown in work [24], leading to the formation of photocatalytic degradation products.

\section{CONCLUSION}

In summary, HA/GEO-activated halloysitebased geopolymers and those without H/GEO activation can be used for photocatalytic degradation of the dye methyl blue. Considering the mechanism of the photodegradation process of methyl blue, it can be classified as Advanced Oxidation Processes (AOPs). The process of photocatalytic degradation of methylene blue on geopolymers consists in the oxidation with a hydroxyl agent of the dye adsorbed on the surface of a catalyst, which is a geopolymer. Fourier Transform Infrared Spectroscopic analysis revealed chemical bonding of methyl blue molecules on the surface of the applied geopolymers. Optimal process conditions were determined $-\mathrm{pH}>10$, time for H/GEO $265 \mathrm{~min}$, and for HA/GEO 125 min for initial dye concentration in the range of $5-100$ $\mathrm{mg} / \mathrm{dm}^{3}$. The equilibrium description of the process occurs for both geopolymers according to the Langmuir isotherm assumptions. The adsorption rate of methyl blue on the surface of geopolymers follows the pseudo-secondary kinetic equation. For the raw halloysite H/GEO-based geopolymer, intramolecular diffusion is the step that determines the rate of blue adsorption, while the adsorption kinetics of this dye on the surface of the activated halloysite geopolymer is determined by diffusion in the liquid phase and intermolecular diffusion.

\section{REFERENCES}

[1] Filipkowska U., Adsorption and desorption of Reactive Dyes onto Chitin and Chitosan Flakes and Beads, Adsorption Science and Technology, Vol. 24, 2006, pp. 781-795.

[2] Pandey A., Singh P., Iyengar L, Bacterial decolorization and degradation of azo dyes, International Biodeterioration and 
Biodegradation, Vol. 59, No. 2, 2007, pp. 73-84.

[3] Rafatullah M., Sulaiman R., Ahmad A., Adsorption of methylene blue on low-cost adsorbents: a review, Journal of Hazardous Materials, Vol. 177, 2010, pp. 70-80.

[4] Unuabonah E.I., Adebowale K.O., Dawodu F.A., Equilibrium, kinetic and sorber design studies on the adsorption of aniline blue dye by sodium tetraborate-modified kaolinite clay adsorbent, Journal of Hazardous Materials, Vol. 157, 2008, pp. 397-409.

[5] Wawrzkiewicz M., Use of various sorbents in removal of dyes from aqueous solutions and industrial wastewaters, Chemical Industry, Vol. 91, 2012, pp. 45-52.

[6] Deng H., Yang L., Tao G., Dai J., Preparation and characterization of activated carbon from cotton stalk by microwave assisted chemical activation-application in methylene blue adsorption from aqueous solution, Journal of Hazardous Materials, Vol. 166, No. 2-3, 2009, pp. 1514-1521.

[7] Bilińska L., Wrębiak J., Ledakowicz S., Ozone as a stage in textile wastewater treatment technology, Engineering and Chemical Apparatus, 54, 2015, pp. 146-147.

[8] Nawrocki J., Fijołek L., Mechanisms and Effi ciency of Catalytic Ozonation in Water Treatment, Environmental Protection, 3, 2009, pp. 3-16.

[9] Dąbek L., Ozimina E., Picheta-Oleś A., Research on Removal of Coloured Organic Compounds from Textile Industry Wastewater, Annual Set The Environmental Protection, 15, 2013, pp. 1164-1176.

[10] Sitarz-Palczak E, Kalembkiewicz J, Galas D., Comparative study on the characteristics of coal fly ash and biomass ash geopolymers, Archives of Environmental Protection, 45, 2019, pp. 126-135.

[11] Hu J.,Dai W., Yan X., Comparison study on the adsorption performance of mrthylene blue and congo red on cu-BTC, Desalination and Water Treatment, Vol. 57, No. 9, 2016, pp. 4081-4089.

[12]Liu Y., Yan C., Zhang Z., Gong Y., Wang H., Qiu X., A facile method for preparation of floatable and permeable fly ash-based geopolymer block, materials letters, Vol. 185. 2016, pp. 370-373.

[13] Novais R.M., Ascesão G., Tobaldi D.M., Seabra M.P., Labrincha J.A., Biomass fly ash geopolymer monolith for effective methylene blue removal from wastewaters, Journal of Cleaner Production, Vol.171, 2017, pp. 783-794.

[14] Khan M.I., Min T.K., Azizli k., Sufian S., Ullah H., Man Z., Effective removal of methylene blue from water using phosphoric acid based geopolymers: synthesis, characterizations and adsorption studies, RCS Advances, Vol. 5, No. 75, 2015, pp. 61410-61420.

[15] Ho Y.S., Mckay G., Pseudo-second order model for sorption process, Process Biochemistry, Vol. 34, 1999, pp. 541-465.

[16] Novais R.M., Buruberri L.H., Seabra M.P., Labrincha J.A., Novel porous fly-ash containing geopolymer monoliths for lead adsorption from wastewaters, Journal of Hazardous Materials, Vol. 318, 2016, pp. 631-640.

[17] Rees C.A., Provis J., Lukey G.C., van Deventer J.S.J., Attenuated total reflectance fourier transform infrared analysis of fly ash geopolymer gel aging, Langmuir, Vol. 23, 2007, pp. 8170-8179.

[18] Lee W.K.W., van Deventer J.S.J., Use of Infrared Spectroscopy to Study Geopolymerization of Heterogeneous Amorphous Aluminosilicates, Langmuir, Vol. 29, 2003, pp. 8726-8734.

[19] Criado M, Fernández-Jiménez A., Palomo A, Alkali activation of fly ash: Effect of the $\mathrm{SiO}_{2} / \mathrm{Na}_{2} \mathrm{O}$ ratio. Part I: FTIR study, Microporous and Mesoporous Materials, Vol. 106, 2007, pp. 180-191.

[20] Kaušpėdienė D., Gefenienè A., Kazlauskienè E., Ragauskas R., Selskienè A., Simultaneous removal of azo and phthalocyanine dyes from aqueous solutions using weak base anion exchange resin, Water, Air, and Soil Pollution, Vol. 224, No. 1769, 2013, pp. 1769-1781.

[21] Houas A., Lachheb H, Ksibi M., Elaloui E., Guillard C, Herrmann J-M., Photocatalytic degradation pathway of methylene blue in water, Applied Catalysis B: Environmental, Vol. 31, No. 2, 2001, pp. 145-157.

[22] Mohanty S., Maji S.K., Adsorption/photodegradation of methylene blue from synthetic wastewater on titanate nanotubes surfaces Water Science\& Technology, Vol. 82, No. 11, 2020, pp. 2562-2575.

[23] Novais R.M., Ascens G., Tobaldi D.M., Seabra M.P., Labrincha J.A., Biomass fly ash geopolymer monoliths for effective methylene blue removal from wastewaters, Journal of Cleaner Production, Vol. 171, 2018, pp. 783794.

[24] Zhang Y., Liu L., Fly ash-based geopolymer as a novel photocatalyst for degradation of dye from wastewater, Particuology, Vol. 11, 2013, pp. 353 - 358.

Copyright (C) Int. J. of GEOMATE All rights reserved, including making copies unless permission is obtained from the copyright proprietors. 